\title{
Impact of dynamic alignment, motion, and center of rotation on myelopathy grade and regional disability in cervical spondylotic myelopathy
}

\author{
Shian Liu, MD, ${ }^{1}$ Renaud Lafage, MS, ${ }^{1}$ Justin S. Smith, MD, PhD, ${ }^{2}$ \\ Themistocles S. Protopsaltis, MD, ${ }^{1}$ Virginie C. Lafage, PhD, ${ }^{1}$ Vincent Challier, MD, ${ }^{1}$ \\ Christopher I. Shaffrey, MD, ${ }^{2}$ Kris Radcliff, MD, ${ }^{3}$ Paul M. Arnold, MD, ${ }^{4}$ Jens R. Chapman, MD, ${ }^{5}$ \\ Frank J. Schwab, MD, ${ }^{1}$ Eric M. Massicotte, MD, ${ }^{6}$ S. Tim Yoon, MD, PhD, ${ }^{7}$ \\ Michael G. Fehlings, MD, PhD, ${ }^{6}$ and Christopher P. Ames, MD ${ }^{8}$
}

\begin{abstract}
'Department of Orthopaedic Surgery, New York University Hospital for Joint Diseases, New York, New York; ${ }^{2}$ Department of Neurosurgery, University of Virginia Medical Center, Charlottesville, Virginia; ${ }^{2}$ Rothman Institute, Egg Harbor Township, New Jersey; ${ }^{4}$ Department of Neurosurgery, University of Kansas Medical Center, Kansas City, Kansas; ${ }^{5}$ Department of Orthopaedic Surgery, University of Washington, Seattle, Washington; ${ }^{6}$ Department of Neurosurgery, Toronto Western Hospital, Toronto, Ontario, Canada; ${ }^{7}$ Emory Orthopaedics and Spine Center, Emory University School of Medicine, Atlanta, Georgia; and ${ }^{8}$ Department of Neurosurgery, University of California-San Francisco Medical Center, San Francisco, California
\end{abstract}

OBJECT Cervical stenosis is a defining feature of cervical spondylotic myelopathy (CSM). Matsunaga et al. proposed that elements of stenosis are both static and dynamic, where the dynamic elements magnify the canal deformation of the static state. For the current study, the authors hypothesized that dynamic changes may be associated with myelopathy severity and neck disability. This goal of this study was to present novel methods of dynamic motion analysis in CSM.

METHODS A post hoc analysis was performed of a prospective, multicenter database of patients with CSM from the AOSpine North American study. One hundred ten patients (34\%) met inclusion criteria, which were symptomatic CSM, age over 18 years, baseline flexion/extension radiographs, and health-related quality of life (HRQOL) questionnaires (modified Japanese Orthopaedic Association [mJOA] score, Neck Disability Index [NDI], the 36-Item Short Form Health Survey Physical Component Score [SF-36 PCS], and Nurick grade). The mean age was $56.9 \pm 12$ years, and $42 \%$ of patients were women $(n=46)$. Correlations with HRQOL measures were analyzed for regional (cervical lordosis and cervical sagittal vertical axis) and focal parameters (kyphosis and spondylolisthesis between adjacent vertebrae) in flexion and extension. Baseline dynamic parameters (flexion/extension cone relative to a fixed C-7, center of rotation [COR], and range of motion arc relative to the $\mathrm{COR}$ ) were also analyzed for correlations with $\mathrm{HRQOL}$ measures.

RESULTS At baseline, the mean HRQOL measures demonstrated disability and the mean radiographic parameters demonstrated sagittal malalignment. Among regional parameters, there was a significant correlation between decreased neck flexion (increased C2-7 angle in flexion) and worse Nurick grade $(R=0.189, p=0.048)$, with no significant correlations in extension. Focal parameters, including increased C-7 sagittal translation over T-1 (slip), were significantly correlated with greater myelopathy severity (mJOA score, Flexion $R=-0.377, p=0.003 ; m J O A$ score, Extension $R=-0.261$, $p=0.027$ ). Sagittal slip at C-2 and C-4 also correlated with worse HRQOL measures. Reduced flexion/extension motion cones, a more posterior COR, and smaller range of motion correlated with worse general health SF-36 PCS and Nurick grade.

CONCLUSIONS Dynamic motion analysis may play an important role in understanding CSM. Focal parameters demonstrated a significant correlation with worse HRQOL measures, especially increased C-7 sagittal slip in flexion and extension. Novel methods of motion analysis demonstrating reduced motion cones correlated with worse myelopathy grades.

ABBREVIATIONS $\mathrm{CL}=\mathrm{C} 2-7$ cervical lordosis; $\mathrm{COR}=$ center of rotation; $\mathrm{CSM}=$ cervical spondylotic myelopathy; $\mathrm{CSVA}=\mathrm{C} 2-7$ sagittal vertical axis; $\mathrm{CTJ}=$ cervicothoracic junction; HRQOL = health-related quality of life; $\mathrm{mJOA}=$ modified Japanese Orthopaedic Association; NDI = Neck Disability Index; ROM = range of motion; SF-36 PCS = 36-Item Short Form Health Survey Physical Component Summary.

SUBMITTED April 24, 2014. ACCEPTED February 5, 2015.

INCLUDE WHEN CITING Published online August 28, 2015; DOI: 10.3171/2015.2.SPINE14414. 


\begin{abstract}
More posterior COR and smaller range of motion were both correlated with worse general health scores (SF-36 PCS and Nurick grade). To our knowledge, this is the first study to demonstrate correlation of dynamic motion and listhesis with disability and myelopathy in CSM.
\end{abstract}

Clinical trial registration no.: NCT00285337 (clinicaltrials.gov)

http://thejns.org/doi/abs/10.3171/2015.2.SPINE14414

KEY WORDS cervical spondylotic myelopathy; health-related quality of life outcomes; dynamic alignment; cone of kinesis; flexion; extension

$\mathrm{C}$ ERVICAL spondylotic myelopathy (CSM) is one of the most common causes of spinal cord dysfunction worldwide. . $21,28,29,42,55$ It is a spinal cord condition with a partially described natural history, and it can be progressive or resume after a period of quiescence. ${ }^{14,35,51}$ CSM causes neurological impairment and functional decline predominantly in the adult population over 55 years of age. . $8,30,37,61,65$ Both static and dynamic elements can factor into the course of this disease. Underlying static factors of stenosis can cause nerve and spinal cord compression leading to CSM. It may also be exacerbated by the repetitive insult of dynamic factors such as those incurred during neck flexion and extension movements. .11,29,34,60,61 $^{2}$

Anterior and/or posterior soft-tissue and bony elements contribute to the static factors that cause stenosis. Protruding discs and ligamentous hypertrophy are examples of soft-tissue mass effects on the spinal canal, whereas agerelated changes in the vertebrae and facets represent the osseous degenerative cascade known as spondylosis. ${ }^{61}$ However, spondylosis itself is not always pathognomonic for CSM. A consecutive autopsy series in 200 adults demonstrated spondylosis in $53.5 \%$ of specimens, with only $7.5 \%$ of these having documented clinical evidence of myelopathy. ${ }^{27}$ Whereas degenerative changes can accumulate with age and affect the spinal canal diameter, there is often more to CSM than is evident from a static MRI study.

Dynamic elements can magnify the static components of canal deformation by ligamentous and osseous pathology. ${ }^{34}$ An already compressed spinal cord can sustain further damage when exposed to longitudinal cord tension in repetitive flexion or extension movements. ${ }^{24,29,40,61} \mathrm{With}$ flexion, the spinal cord is draped over the vertebral bodies and can be compressed against osteophytic spurs and protruding discs. ${ }^{1,53,61}$ With hyperextension, the ligamentum flavum or laminae can pinch the spinal cord posteriorly against the posterior margin of the vertebral body anteriorly. ${ }^{52,60,61}$ Over time, these repetitive movements can cause irreversible changes in the spinal cord, ${ }^{11,43,50}$ which is perhaps why some patients may not improve after decompression, but rather experience a plateau of previously deteriorating symptoms.

Furthermore, these motion-related factors not only reduce space, but can also compromise capillaries and microvasculature that maintain a steady supply of oxygen and nutrients to the spinal cord. ${ }^{4,61}$ The accumulation of degenerative changes affects the canal diameter, as well as the sagittal mobility of the spine, ${ }^{29}$ leading to acute neu- ropathological changes that culminate in disease. Even patients with conditions that have nondegenerative etiologies, such as athetoid-dystonic conditions, ${ }^{19,20}$ cervical dystonia ${ }^{25}$ or achondroplasia, ${ }^{48,64}$ as well as rugby players with repeated, forced flexion and extension positions, can experience accelerated spondylosis ${ }^{7}$ with dynamic motionrelated development of CSM.

Static and dynamic factors affect the natural history in many spinal pathologies globally and focally. Considering the entire spinal column and the head and trunk in its entirety, Dubousset visualized a conus of balance for the standing position, in which the feet are located within a zone called the "polygon of sustentation" and the body, under the influence of muscle function and ligamentous support, can move in a conical fashion without moving the feet. ${ }^{15} \mathrm{He}$ further described the concept of a "conus of economy," where the body can stay balanced with minimal muscle action. ${ }^{15}$ With this model in mind, we propose to visualize the dynamic cervical spine in patients with CSM as a "cone of kinesis" for the purposes of examining the pathology in a kinetic fashion.

An appreciation of the dynamic contributions to the pathobiology of CSM is acknowledged in the literature. However, there is a paucity of data that attempt to convert these dynamic motions into quantifiable parameters, and even fewer data exist that try to correlate the dynamic aspects of CSM with disease- and region-specific scores. To our knowledge, this is the first study that attempts to evaluate and correlate the relationship between dynamic radiographs and myelopathy severity and neck disability using traditional and novel methods of motion analysis in a baseline cohort of symptomatic patients with CSM. Regional, focal, and dynamic parameters all contribute to delineating the pathology of this disease.

\section{Methods \\ Study Design and Inclusion/Exclusion Criteria}

This study is a post hoc analysis of a prospective, multicenter database of 302 patients with symptomatic CSM across 12 surgical spine centers in North America. Participating centers are contributing members to the AOSpine North America Clinical Research Network, a nonprofit organization dedicated to developing research and expanding education on spinal pathologies. Institutional review board approval and patient informed consent was obtained from all sites and is registered with clinicaltri- 
als.gov under clinical trial registration no. NCT00285337. Criteria for inclusion were baseline flexion and extension radiographs of the cervical spine (Fig. 1), baseline healthrelated quality of life (HRQOL) questionnaires, Nurick grade, symptomatic CSM (with clinical signs of myelopathy), cervical cord compression evidenced on MRI or CT myelography, and age 18 years or older. Patients with prior surgical treatment for CSM or symptomatic lumbar stenosis were excluded.

\section{Data Collection}

Available patient demographic data included age, sex, and medical comorbidities. Nurick grade and HRQOL measures were recorded preoperatively and included modified Japanese Orthopaedic Association (mJOA) scores, the Neck Disability Index (NDI), and the 36-Item Short Form Physical Component Summary (SF-36 PCS). Nurick grade is a clinical score for myelopathy severity determined by the physician, and ranges from Grade 0 (best) to Grade 5 (worst); ${ }^{42} \mathrm{mJOA}$ score is a patient-reported outcome specific for myelopathy severity and ranges from 0 (worst) to 18 (best); ${ }^{6} \mathrm{NDI}$ is a patient-reported outcome specific for neck disability and ranges from 0 (best) to 100 (worst); ${ }^{12,62,63}$ SF-36 PCS is also a multipurpose, patientreported outcome that measures the burden of disease and ranges from 0 (lowest level of health) to 100 (highest level of health)..$^{10,12}$

\section{Radiographic Analysis}

Radiographic anatomical landmarks were ascertained at baseline by demarcating the margins of the superior endplate, inferior endplate, and posterior tangent line of each vertebral body on full cervical flexion and extension

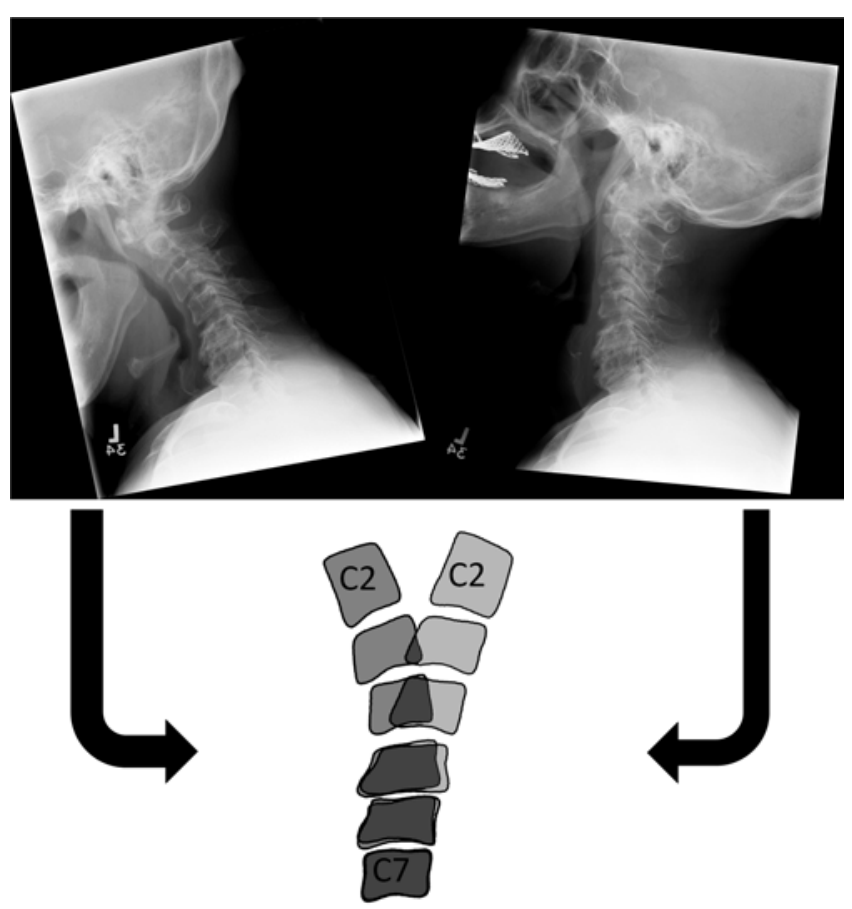

FIG. 1. Full flexion and extension radiographs of the cervical spine. For the dynamic analysis, radiographs were superimposed at a fixed C-7. radiographs using SpineView software (Laboratory of Biomechanics, ENSAM) and analyzed using MATLAB software (MathWorks); calibration for linear measurements was obtained using the height of C-3 as $17.7 \mathrm{~mm} .{ }^{66}$ Digitalization of each vertebral endplate on the sagittal flexion and extension radiographs from $\mathrm{C}-7$ to the cranium permitted calculation of both regional and focal parameters. Regional parameters included C2-7 cervical lordosis (cL) and C2-7 sagittal vertical axis (cSVA). The cSVA was measured as the horizontal distance between a plumb line dropped from the center of the C-2 vertebral body and the posterior-superior corner of C-7. ${ }^{59}$ Focal parameters between adjacent cervical vertebrae included number of kyphotic levels and spondylolisthesis (also acknowledged as sagittal translation, or slip of 1 vertebra over another). Slip was treated as a continuous variable expressed in millimeters.

Traditional methods for dynamic analysis, such as center of rotation (COR) and range of motion (ROM), were also used. COR, calculated from a dynamic C-2 with the Bogduk method, which he referred to as the instantaneous axis of rotation,, 94 was determined from the perpendicular bisectors of the lines drawn from the anterior-inferior corner of $\mathrm{C}-2$ in flexion to extension and the posterior-inferior corner of C-2 in flexion to extension (Fig. 2). Initially, the instantaneous axis of rotation of each individual vertebra was calculated through a series of radiographs to obtain a cumulative "centrode of motion,"2,9,17,47 but this method is associated with large technical errors because of the small increments of angular displacement. ${ }^{3,32,45,57}$ However, the Bogduk method can be applied in full flexion and extension of the cervical spine to consider the physiological movement of the region as a whole., $3,9,32$

COR was quantified with a cephalad/caudal component and an anterior/posterior component to locate its central moment along the cervical spine using the posterior-superior corner of C-7 as the reference point; to produce the coordinates for the COR, these distances were normalized to the height and width of C-7 for each patient to standardize individual differences. An ROM arc was also calculated for each patient, relative to the COR.

Novel methods for dynamic parameters were also developed to better visualize and conceptualize the motion of the cervical spine in 1 parameter. This cone of kinesis is a cone computed from a fixed C-79,24 to the position of $\mathrm{C}-2$ in flexion and extension. This flexion/extension cone is composed of both a flexion/extension area (integrated area between the spline in flexion and the spline in extension) and a flexion/extension angle (Fig. 3). The spline is computed to cross every vertebral center in the cervical spine and is a continuous series of cubic interpolations along each segment. ${ }^{36,56}$

\section{Statistical Analysis}

The data were analyzed using SPSS version 17.0 software (IBM). Descriptive statistics were used to characterize mean age, sex distribution, baseline radiographic parameters (regional, focal, and dynamic), baseline Nurick grade, and baseline HRQOL measures. Pearson correlations between radiographic parameters (regional and focal) in flexion and extension with HRQOL measures were 


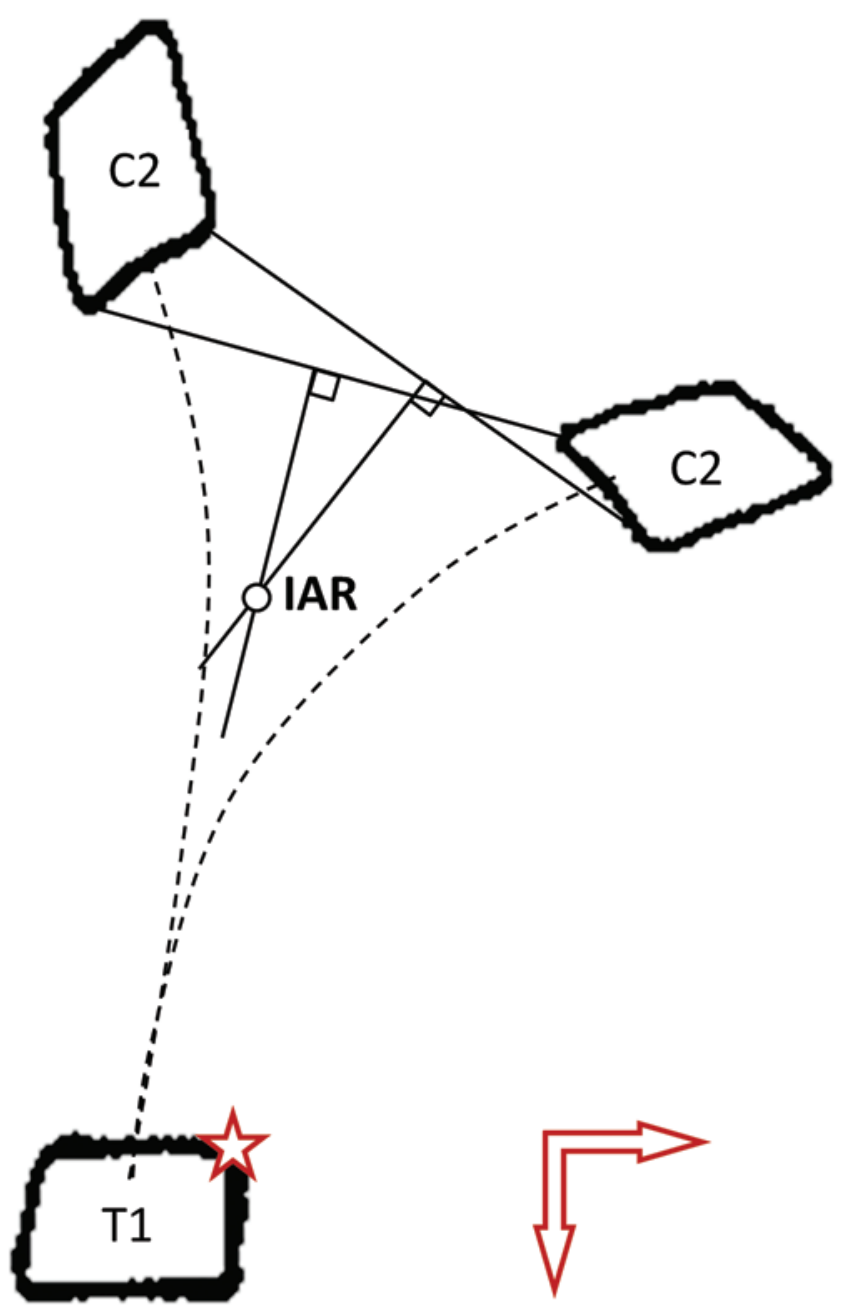

FIG. 2. COR of the entire cervical spine using the Bogduk method in full flexion and extension. Posterior-superior corner of C-2 used as the reference point. The star denotes the origin of the reference system. IAR = instantaneous axis of rotation. Figure is available in color online only.

conducted. Pearson correlations between dynamic parameters with HRQOL measures were also conducted. A p value $<0.05$ was considered statistically significant.

\section{Results}

\section{Patient Population}

A total of 110 patients with CSM from the AOSpine North America study database met inclusion criteria for this analysis. The average age was $56.9 \pm 12.0$ years and $42 \%$ of patients were women $(n=46)$. The mean duration of symptoms at baseline was 28.4 months.

\section{Baseline Presentation: Nurick Grade, HRQOL Measures, and Sagittal Alignment}

Mean Nurick grade and HRQOL measures demonstrated disability at baseline. More than $90 \%$ of patients (n $=100$ ) presented clinically with a Nurick grade between 1 and 3 at baseline (Table 1). Patient-reported outcomes supported this clinical evaluation with an mJOA score of 13.0 \pm 2.9 , an NDI of $42.5 \pm 20.7$, and an SF-36 PCS $34.7 \pm 10.1$.
The mean regional radiographic parameters demonstrated sagittal malalignment. In extension, the mean cSVA was $10.1 \pm 13.2 \mathrm{~mm}$ and $\mathrm{cL}$ was $22.7^{\circ} \pm 11.6^{\circ}$. In flexion, the mean cSVA was $48.2 \pm 12.4 \mathrm{~mm}$ and $\mathrm{cL}$ was $-14.8^{\circ} \pm 12.7^{\circ}$. The mean cSVA in flexion was above the threshold of cervical alignment, defined as $40 \mathrm{~mm}$ in the sagittal plane. ${ }^{59}$

\section{Correlations: Regional, Focal, and Dynamic Parameters}

Regarding regional parameters, there was a significant positive correlation between a larger $\mathrm{cL}$ in flexion and worse Nurick grade $(R=0.189, p=0.048)$, with no significant correlations in extension and Nurick grade or HRQOL measures (Table 2).

Focal parameters were also significantly correlated with disability (Table 2). C-7 sagittal slip (defined as listhesis between C-7 and T-1) correlated with worse mJOA score in flexion $(\mathrm{R}=-0.377, \mathrm{p}=0.003)$ and extension $(\mathrm{R}$ $=-0.261, \mathrm{p}=0.027)$. Translational slips at other levels also correlated with myelopathy severity and disability: C-4 sagittal slip correlated with worse NDI $(\mathrm{R}=0.281$, $\mathrm{p}=0.004)$ and SF-36 PCS in extension $(\mathrm{R}=-0.259, \mathrm{p}=$ 0.010 ); worse C-2 slip in extension correlated with worse mJOA score $(\mathrm{R}=-0.195, \mathrm{p}=0.042)$; and maximum slip in extension also correlated with worse mJOA score $(-0.241$, $\mathrm{p}=0.011)$. In terms of number of kyphotic levels, there were no correlations in extension, but in flexion, there were significant correlations with Nurick grade $(\mathrm{R}=-0.296, \mathrm{p}$ $=0.002)$ and $\mathrm{mJOA}$ score $(\mathrm{R}=0.249, \mathrm{p}=0.009)$.

Dynamic parameters (Fig. 4) also correlated with HRQOL measures: worse Nurick grade correlated with smaller flexion/extension cone area $(R=-0.261, p=0.041)$ and smaller flexion/extension cone angle $(\mathrm{R}=-0.251, \mathrm{p}=$ 0.049 ); worse SF-36 PCS correlated with a more posterior COR $(\mathrm{R}=-0.319, \mathrm{p}=0.016)$ and smaller $\mathrm{ROM}(\mathrm{R}=0.418$; $\mathrm{p}=0.007$ ). A smaller ROM also correlated with a worse Nurick grade $(R=-0.266, p=0.038)$ when this dynamic analysis was conducted from a fixed T-1 (instead of a fixed C-7).

Further analysis of the dynamic parameters revealed that both cone area and cone angle correlated with age, with smaller cones as age increases (cone area and age $\mathrm{R}$ $=-0.395, \mathrm{p} \leq 0.001$; cone angle and age $\mathrm{R}=-0.442, \mathrm{p} \leq$ $0.001)$. There was also a significant correlation between a larger cone angle and a more distal COR along the cervical spine $(\mathrm{R}=0.268, \mathrm{p}=0.035)$. There was no correlation between the cone of kinesis (cone area and cone angle) and ROM.

\section{Discussion}

The key findings in this analysis were regional, focal, and dynamic radiographic slight but significant correlations with HRQOL measures or Nurick grade. Among regional parameters, there was a significant correlation between increased cL in flexion and Nurick grade $(\mathrm{R}=$ $0.189, \mathrm{p}=0.048$ ), with no significant correlations in extension. Focal parameters, especially C-7 sagittal slip, were significantly correlated with myelopathy severity (mJOA score, Flexion $\mathrm{R}=-0.377, \mathrm{p}=0.003$; mJOA score, Extension $R=-0.261, p=0.027)$. Other focal parameters, 


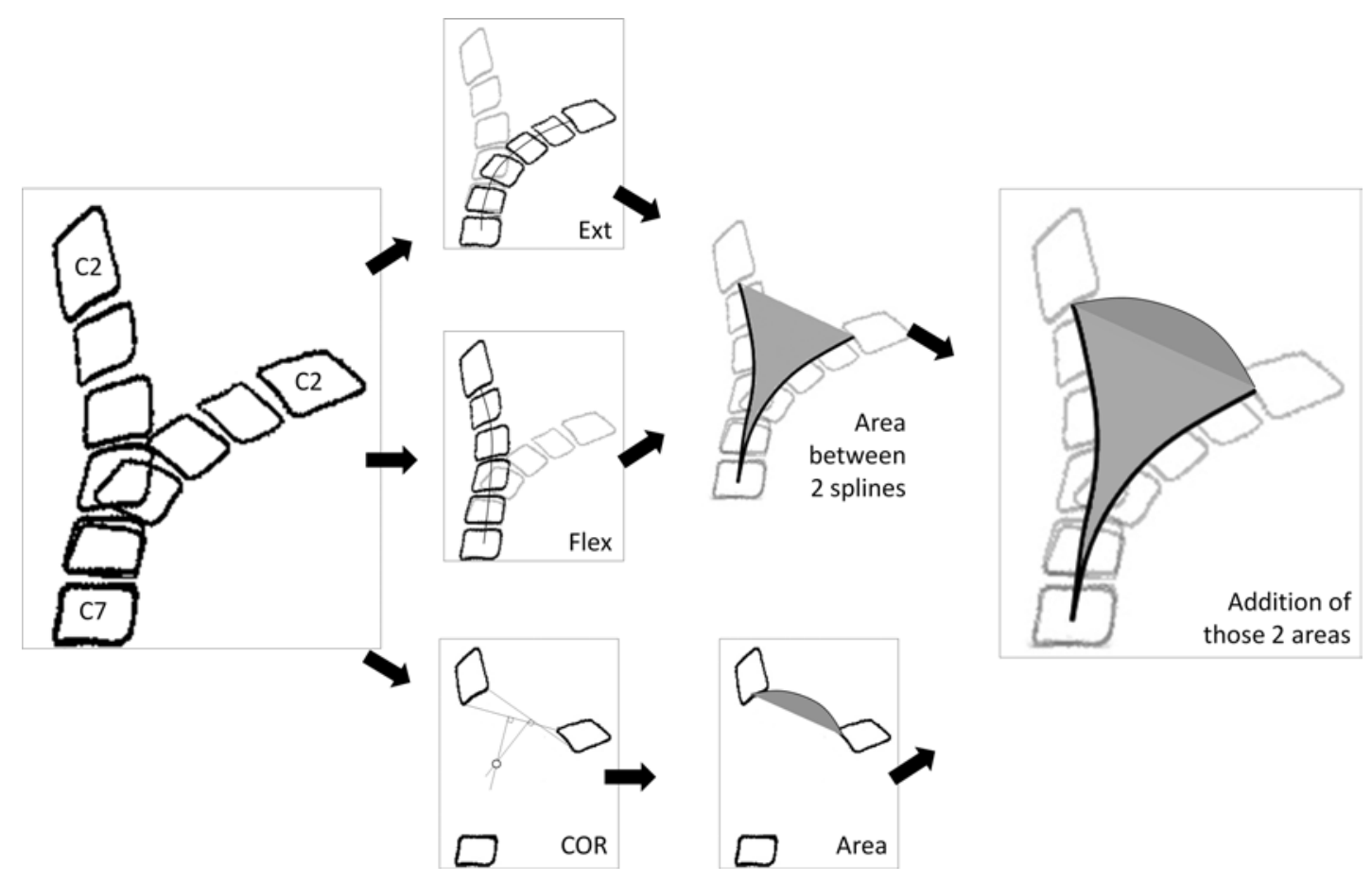

FIG. 3. Cone of kinesis (flexion/extension cone) calculated from a fixed C-7 using the area and angle between the splines. Ext = extension; Flex = flexion.

including C-4 slip and C-2 slip, also correlated with worse HRQOL measures. Finally, reduced flexion/extension motion cones, a more posterior COR, and smaller range of motion correlated with worse general health (SF-36 PCS) and Nurick grade. The correlations were globally weak but comparable with such found in the literature..$^{55,59}$

\section{Background}

This dedicated ROM analysis in a baseline cohort of patients with symptomatic CSM attempted to evaluate regional, focal, and dynamic parameters, which all correlated with some quantifiable measure of disease severity. Biomechanical and motion-related factors can transiently compress the spinal cord, nerve roots, and their vascular supply, ${ }^{11,29,50,53}$ and the importance of this dynamic motion has been studied previously. Park et al. studied the ROM in the cervical spine after extensive fusion, with a methodology using the occipitocervical angle (made by the anterior cervical fusion mass and the McGregor line) and the cervicosternal angle (made by the anterior cervical fusion

TABLE 1. Baseline Nurick grades among 110 patients with CSM

\begin{tabular}{ccl}
\hline $\begin{array}{c}\text { Nurick } \\
\text { Grade }\end{array}$ & $\begin{array}{c}\text { No. of } \\
\text { Patients (\%) }\end{array}$ & \multicolumn{1}{c}{ Clinical Presentation } \\
\hline 0 & $4(4 \%)$ & $\begin{array}{c}\text { Root signs or symptoms. No evidence of cord } \\
\text { involvement. }\end{array}$ \\
\hline 1 & $26(24 \%)$ & Signs of cord involvement. Normal gait. \\
\hline 2 & $43(39 \%)$ & Mild gait abnormality. Able to be employed. \\
\hline 3 & $31(28 \%)$ & Gait abnormality prevents employment. \\
\hline 4 & $5(5 \%)$ & Able to ambulate only w/ assistance. \\
\hline 5 & $1(<1 \%)$ & Chair bound or bedridden. \\
\hline
\end{tabular}

mass and the anterior border of the sternum) in flexion and extension. ${ }^{46}$ Similarly, Fujimori et al. examined the ROM after laminoplasty by simply looking at the difference between $\mathrm{cL}$ in flexion and extension, ${ }^{22}$ which, in our study, did not correlate with severity of myelopathy. These studies propose methods for analyzing dynamic motion. However, no prospective study has delved into a large population of patients with CSM and carefully examined their baseline presentation on the regional and focal levels.

\section{Regional Abnormalities and ROM}

When considering the cervical spine in its entirety on a regional level, increased $\mathrm{cL}$ in flexion correlated with a poor Nurick grade. There were no correlations with any regional parameters and Nurick grade or HRQOL measures in patients with a cervical spine aligned in extension at baseline. All prior studies have found that with active flexion, the length of the canal increases. As a result, the cord and dura are stretched beyond their normal tension with an unequal distribution and held against spondylotic protrusions, ${ }^{11,43,50}$ whereas in extension, the cervical spinal cord is relaxed and flaccid..$^{11}$ It is possible that the patient with CSM may be instinctively guarding the cord against further longitudinal tension by maintaining some extension in flexion. ${ }^{11}$ Alternatively, increased $\mathrm{cL}$ in flexion may result from increased rigidity due to spondylosis.

Cervical lordosis in a posture of maximum flexion is perhaps intuitively peculiar (see Fig. 5). Tang et al. explained that in the presence of positive cervical sagittal alignment, the cervical spine may adopt drastic changes in curvature, namely hyperlordosis of C1-2 as a compensatory mechanism when Dubousset's conus of economy concept was applied to the cervical spine. ${ }^{15,59}$ Moreover, 
TABLE 2. Correlations between radiographic parameters and clinical outcomes*

\begin{tabular}{|c|c|c|c|c|}
\hline \multirow[b]{2}{*}{ Radiographic Parameters } & \multicolumn{4}{|c|}{ Clinical Outcomes } \\
\hline & Nurick Grade & mJOA & NDI & SF-36 PCS \\
\hline \multicolumn{5}{|c|}{ Focal \& regional (flexion/extension) } \\
\hline $\mathrm{cL}$ & $0.189 / \mathrm{NS}$ & NS/NS & NS/NS & NS/NS \\
\hline No. kyphotic levels & $-0.296 / \mathrm{NS}$ & $0.249 / \mathrm{NS}$ & NS/NS & NS/NS \\
\hline C-7/T-1 slip & NS/NS & $-0.377 /-0.261$ & NS/NS & NS/NS \\
\hline C-3/C-4 slip & NS/NS & NS/NS & $\mathrm{NS} / 0.281$ & NS/-0.259 \\
\hline C-2/C-3 slip & NS/NS & NS/-0.195 & NS/NS & NS/NS \\
\hline Max slip & NS/NS & $\mathrm{NS} /-0.241$ & NS/NS & NS/NS \\
\hline \multicolumn{5}{|l|}{ Dynamic } \\
\hline Cone area & -0.261 & NS & NS & NS \\
\hline Cone angle & -0.251 & NS & NS & NS \\
\hline CORap & NS & NS & NS & -0.319 \\
\hline ROM & NS & NS & NS & 0.418 \\
\hline
\end{tabular}

CORap = anteroposterior component of the position of the COR in regard to C-7; NS = not significant.

* Statistical correlations (R values) between radiographic parameters and clinical scores.

with increasing age, patients with CSM have a decreased ROM with stiff soft tissues to maintain the head-neck complex in an optimal position; ${ }^{66}$ the patient may not realize his full ROM in flexion because of habitually holding a stiff neck. ${ }^{17,43}$ This study also found a correlation between decreased ROM and a higher Nurick grade. The authors

C1

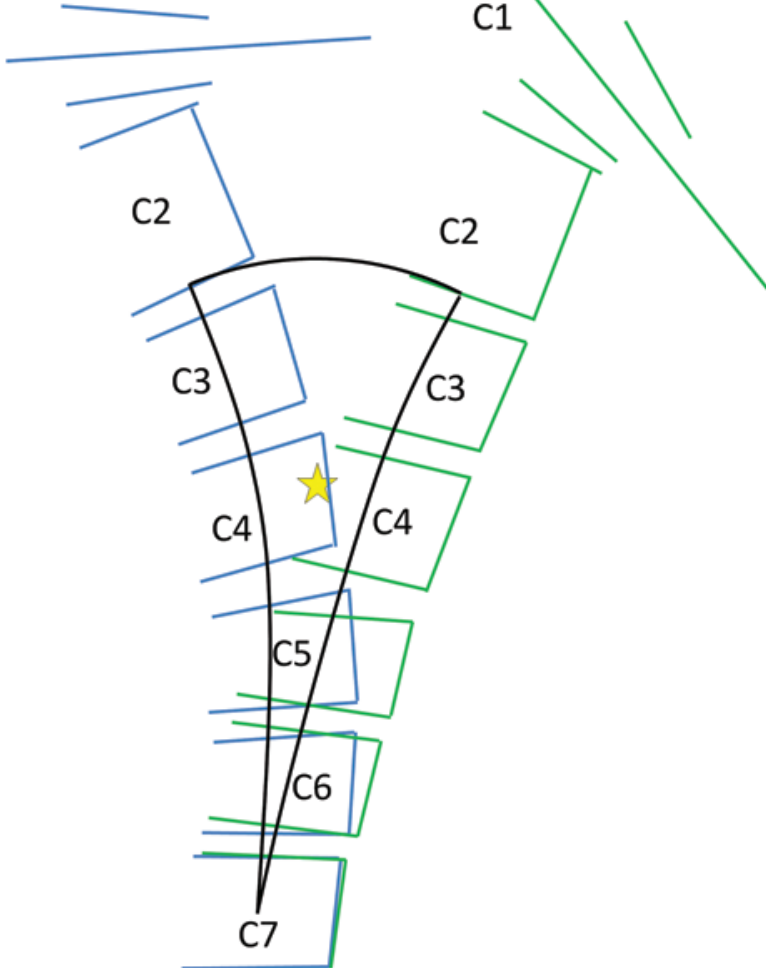

FIG. 4. Dynamic parameters and correlations with $H R Q O L$ measures or Nurick grade. COR is denoted by the star; flexion/extension cone area and angle calculated from a fixed C-7 position; ROM calculated from the COR. Figure is available in color online only. hypothesized that abnormal lordosis in flexion could be due to a patient's attempt to minimize cord tension and distortion, compensate for deformity, or be a reflection of an overall decreased ROM and constitutively tense soft tissues.

\section{Focal Abnormalities}

Matsunaga et al. stated that static pathology is exacerbated by dynamic elements, and the data in this study support their assertion on a focal level. ${ }^{34}$ The role of focal deformity, specifically listhesis (probably degenerative spondylolisthesis in this patient population) and focal kyphosis, in symptomatology is highlighted during dynamic

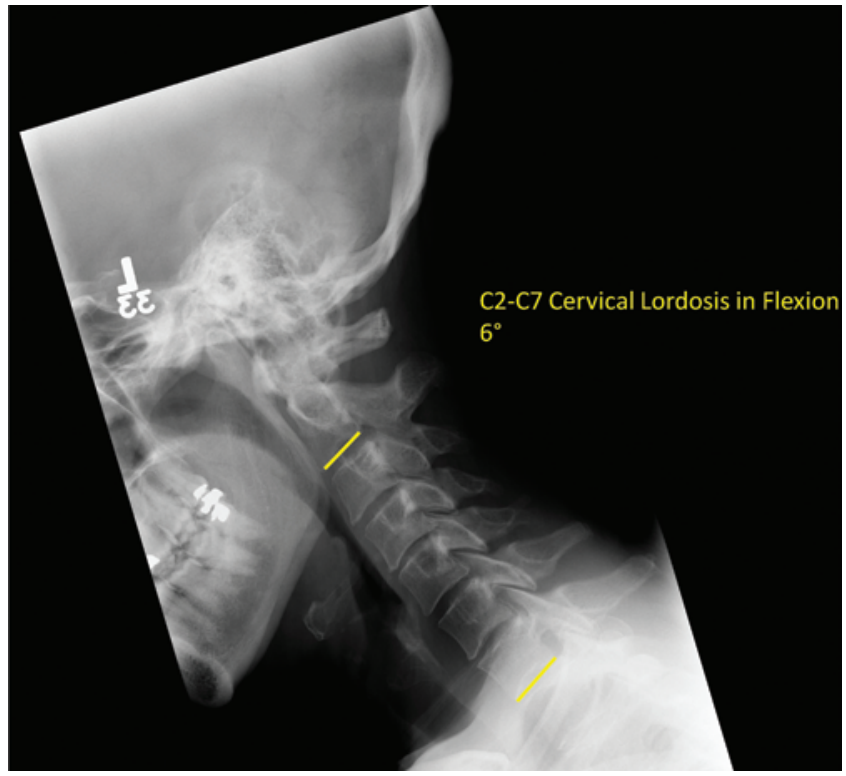

FIG. 5. Example of a patient with $6^{\circ}$ of $\mathrm{CL}$ in maximum flexion. Figure is available in color online only. 
neck motion. Sagittal listhesis can lead to narrowing of the cervical canal, which by itself may exacerbate myelopathy. The interactions of these factors all contribute to the myelopathic picture. The relative contribution of sagittal slip compared with canal stenosis is, perhaps, a mixed picture.

Sagittal slip at C7-T1 in both flexion and extension correlated with a worse mJOA score. As it is where the mobile neck transitions to a more fixed thoracic barrel, the cervicothoracic junction (CTJ) is a biomechanically complex area. Bony destruction due to neoplasm or trauma, or surgical decompression at this location, can result in major concern for spinal instability. ${ }^{31,43,58} \mathrm{~A}$ biomechanical cadaveric study by Stemper et al. demonstrated that lower cervical joints are subjected to greater motion and higher likelihood of injury in rear-impact motor vehicle accidents, mainly because the inertial loading is transferred from the seat to the CTJ. ${ }^{58}$ It is no wonder that this transition zone where the lordotic cervical spine blends to the kyphotic curvature of the thoracic spine is a structurally critical area that is susceptible to many kinds of insults. ${ }^{13,49}$ Furthermore, Cho et al. found that lower cervical laminae are thinner and weaker compared with upper thoracic vertebrae, again demonstrating another anatomical point of inflection that can be exploited by traumatic or repetitive motion. ${ }^{13,43}$ Within the surgical literature for CSM, fusions ending at C-7 raise concern about instability and adjacentsegment disease, ${ }^{26,31}$ our findings that listhesis at the CTJ correlates with a worse mJOA score in CSM suggest that stability between C-7 and T-1 is related to myelopathy severity.

Moving cephalad in the cervical spine (sagittal slip at C4-5) correlated with a worse NDI and SF-36 PCS in extension. Not only is $\mathrm{C} 4-5$ one of the most common places of cord compression in the cervical spine for patients with CSM, second only to C6-7, 23,33,61 but Morio et al. retrospectively noted that restriction of C4-5 ROM after laminoplasty improved clinical myelopathic symptoms. ${ }^{38}$ They also found a significant correlation with $\mathrm{C} 4-5$ intervertebral ROM and JOA score at final postoperative follow-up $(\mathrm{R}=-0.305, \mathrm{p}=0.031),{ }^{38}$ highlighting the impact of stabilizing this focal area.

An increased maximum sagittal slip at any cervical level, as well as an increased C2-3 slip, correlated with a worse mJOA score in extension. Although the cord is more lax in extension than in flexion, it can still be compressed between a spondylotic ridge and laminae or a buckled ligamentum flavum. ${ }^{11,61}$ Oshima et al. found that the existence of local slip was a prognostic factor for surgery in patients with mild CSM. ${ }^{44}$ Myelopathy severity can and does correlate with extreme sagittal plane translation regardless of the cervical level, with the element of extension bringing out the compressive, focal aspect of the disease.

Finally, more segments with focal kyphosis also correlated with a worse Nurick grade and mJOA score in flexion. CSM arises from either a single- or multilevel disease process, particularly in an older population. ${ }^{5,35}$ Shinomiya et al., in an experimental study using cats as models of myelopathy induced by anteriorly applied screws, demonstrated that spinal cord compression at multiple levels caused more severe deterioration functionally and histologically than a single-level compression. ${ }^{54}$ This study did not examine the actual frequency and places of compression in the spinal cord, but focal kyphosis clearly and significantly correlates with clinically apparent and patientexperienced myelopathy severity, especially when multiple areas of focal kyphosis exist along the cervical spine.

Taken together, these results on focal abnormalities suggest that spondylolisthesis at C2-3 and C7-T1 are associated with myelopathy severity. There is limited comparative literature regarding best fusion levels in patients who undergo multilevel cervical laminectomy and fusion. Some surgeons routinely select C3-7 and others C2-T1. Surgeons may consider these findings regarding instability at $\mathrm{C} 2-3$ and $\mathrm{C} 7-\mathrm{T} 1$ when determining posterior fusion levels for patients with CSM.

\section{Dynamic}

While listhesis and axial rotation are all part of the motion of the cervical spine, its prominent motion is flexion and extension due to the alignment of the zygapophyseal joints and the presence of the uncinate processes. ${ }^{18}$ Traditional dynamic parameters such as COR and ROM (as addressed earlier with regional parameters) attempt to quantify the significance of the flexion and extension, and have correlated with HRQOL measures in this study. A more posterior COR (anterior to posterior along a cervical vertebral body) correlated with a worse SF-36 PCS. Although prior work exists on abnormal and normal locations of instantaneous axis of rotations, to our knowledge, no study has correlated COR with any HRQOL measures in patients with symptomatic CSM.

Dvorák et al. performed extensive analysis of flexion and extension radiographs among patients with degenerative changes, radicular syndromes, whiplash trauma, and prior normative data. ${ }^{16-18}$ They found a trend for a more anterior instantaneous axis of rotation for each vertebra throughout a series of radiographs in the patient cohorts compared with a healthy population. ${ }^{17}$ Lee et al. found that patients with an unstable cervical spine also had a headneck axis of rotation that was more anterior than a healthy population, using motion-analysis equipment instead of radiographic data. ${ }^{32}$ These data may appear contrary to the conclusions drawn from this study, which show that a more posterior COR is associated with a lower physical capacity. But it is important to recognize that COR, when applied to a pair of flexion-extension radiographs, is vastly different than looking at the "centrode of motion" (made up of many instantaneous axis of rotations calculated from several radiographs spanning the range from flexion to extension and, as mentioned in Methods, prone to error). When the Bogduk method is applied to the cervical spine as a whole, it reflects the quality of movement of the entire cervical spine along with each intervertebral segment. ${ }^{9,32}$ The cardinal determinant of where this center falls is determined by the compression forces of the muscles and compression stiffness of the discs. ${ }^{9}$ Increased posterior muscle force tends to displace the center backward. If the anterior stiffness of the disc is reduced, the center would also shift posteriorly. Thus, a more posteriorly located COR could be indicative of a collective stiffness of the posterior soft tissues as well as increased disc stiffness in any disc(s) from $\mathrm{C} 2-7$. 
Amevo et al. delineated a normal zone (within which the internal axis of rotation could fall), circumscribed by an abnormal zone, thereby eliminating the anterior versus posterior comparison. ${ }^{2}$ They found that subjects with neck pain were significantly more likely to fall into the abnormal zone than the healthy population. ${ }^{2}$ These studies suggest that there is a difference between the COR of pathological and nonpathological cervical motion. However, further study, based on simple and accurate methodology, is needed to define what constitutes a pathological COR.

To conceptualize and visualize the flexion and extension motion of the cervical spine as a whole and its contributions to the clinical presentation (Fig. 6), Dubousset's concept of a "cone of balance" was applied to a region of the spinal column. As we alluded to in the introduction, Dubousset asserts that there exists a conus within which the whole body can maintain an upright posture. The cone of economy represents the minimal amount of exertion; the cone of maximum work represents the upper limit of the cone; ${ }^{15}$ and the body adapts to changes in balance to regulate the center of gravity over as narrow a perimeter as possible..$^{59}$ Dubousset does not imply what is pathological or normal but simply asserts that the greater the cone, the more muscular effort is involved.

The data from this study demonstrated that a smaller cone of kinesis (the dynamic cone of the cervical spine as measured by an angle and an area from a fixed C-7) is correlated with a worse Nurick grade. Furthermore, smaller cones also correlate with increased age, which is consistent with prior data showing that CSM occurs more

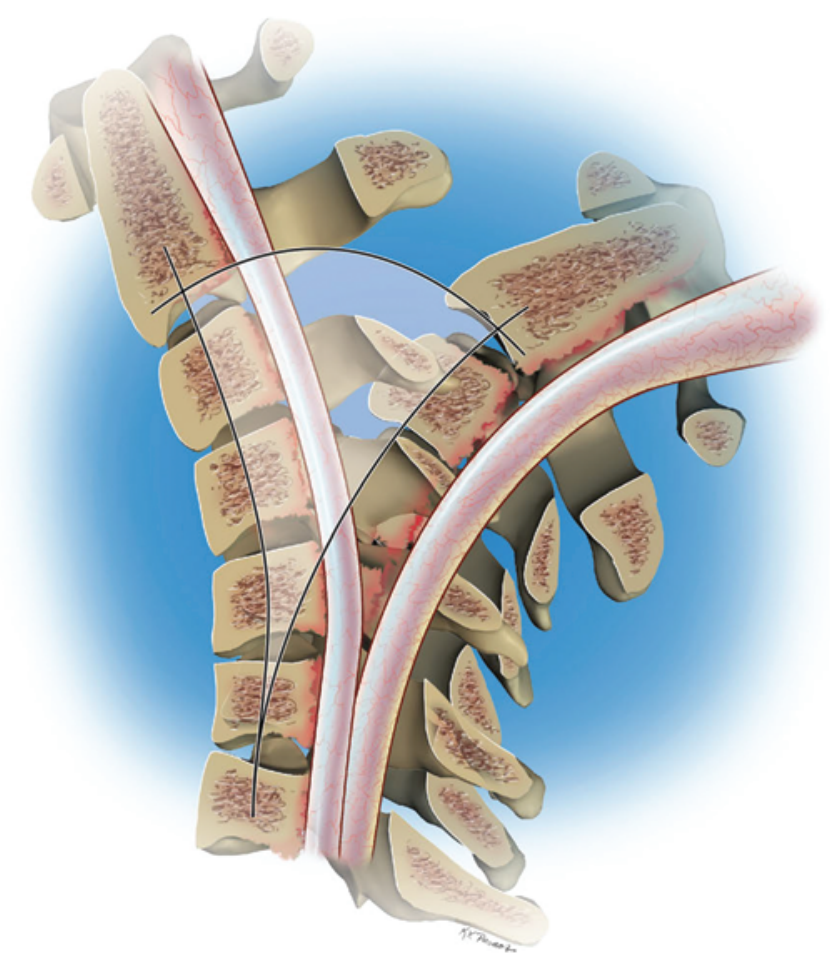

FIG. 6. Cone of kinesis, an application of Dubousset's cone of economy concept, to visualize flexion and extension motion of the cervical spine and conceptualize dynamic pathological contributions to the clinical presentation. Courtesy of Kenneth X. Probst/Xavier Studio, 2014. Published with permission. Figure is available in color online only. frequently in older individuals. ${ }^{5,35}$ Patients with smaller cones may have a normal ROM for their age and sex but are potentially guarding their cords from tension or compression, in addition to the reduction of motion due to spondylotic changes. Also, patients with a particularly long symptomatic period before presentation may have exercised active or reflexogenic muscular restraint for so long that they have subsequent soft-tissue stiffening. For these patients, to move outside of this cone would require recruitment of more muscles, which are either chronically overcontracted or underused. ${ }^{15,17}$ Loss of cone size may be more a consequence of neurological compression and not necessarily the inability to move, culminating in a cycle of intentional hypomobility and stiffness. In a sense, surgery attempts to achieve what the patients are already doing in the course of their disease: stabilizing sagittal movement of the cervical spine. ${ }^{24}$

\section{Limitations and Future Work}

Radiographic analysis is subject to errors of magnification and is a primary limitation of this study, along with the lack of information on the spinal cord and soft tissues. Prior kinematic work by Morishita et al..$^{39}$ has evaluated patients in flexion and extension by positional MRI. However, this is not always feasible at many medical and research centers and may exclude a subset of patients with severe myelopathy who may not be able to hold an extreme position for the period of time required for image acquisition. Additionally, the Pavlov ratio has been used to account for variability in magnification. However, this was not included in the current analysis because sagittal diameter of the spinal canal was not a primary focus. This study is also limited by the fact that radiographic evidence of spondylosis is quite ubiquitous in the general population. $8,23,33,43,61$ Thus, the findings in this study may not have rendered cervical radiographs more directly useful in a clinical setting, but hopefully serve as a reminder that even simple imaging techniques are potentially rich with scientifically enlightening information.

Future work should focus on applying this dynamic analysis to pre- and postoperative dynamic radiographs to describe the postoperative relationships of dynamic parameters with mJOA score and Nurick grade. Perhaps defining a neutral point and examining the cone proportions from flexion to neutral and from neutral to extension would provide insight into the distribution of conic motion. It could also be important to apply this dynamic analysis to an asymptomatic group of patients with radiographic evidence of stenosis and attempt to better characterize the natural course of disease to help define who is likely to develop progressive CSM.

A comparison of this study population to an age- and sex-matched normative population would also provide valuable insight into the differences between a pathological and nonpathological population in terms of cone area, cone angle, COR, and age. Finally, given that lumbar stenosis can occur in tandem with CSM,${ }^{41,43}$ a similar dynamic analysis of the lumbar spine may provide analogous information and push the frontiers of research into a more global design that appreciates the musculoskeletal system in its entirety. 


\section{Conclusions}

Regional, focal, and dynamic parameters all correlated with either a patient-reported outcome or a physicianscored assessment of myelopathy severity. Increased C2-7 lordosis in flexion correlated with a worse Nurick grade. Focal parameters such as increased listhesis, especially at the CTJ, and increased frequency of focal kyphosis also correlated with worse scores in both flexion and extension. Dynamic parameters, both traditional and novel, also correlated with a worse Nurick grade. Traditional parameters, such as a smaller ROM, correlated with worse Nurick grade, whereas a more posterior COR using traditionally outlined methods correlated with a worse SF-36 PCS. Novel parameters demonstrated that a smaller cone of kinesis, or a reduced flexion/extension motion cone, significantly correlated with a worse Nurick grade, demonstrating with Dubousset's cone of economy that pathological means of achieving stability may develop in CSM even before surgical attempts at stabilization.

\section{Acknowledgment}

We would like to thank Kenneth Probst for his artistic expertise.

\section{References}

1. Ames CP, Blondel B, Scheer JK, Schwab F, Le Huec JC, Massicotte EM, et al: Cervical radiographic alignment: comprehensive assessment techniques and potential importance in cervical myelopathy. Spine (Phila Pa 1976) 38 (22 Suppl 1):S149-160, 2013

2. Amevo B, Aprill C, Bogduk N: Abnormal instantaneous axes of rotation in patients with neck pain. Spine (Phila Pa 1976) 17:748-756, 1992

3. Amevo B, Macintosh JE, Worth D, Bogduk N: Instantaneous axes of rotation of the typical cervical motion segments: I. an empirical study of technical errors. Clin Biomech (Bristol, Avon) 6:31-37, 1991

4. Baron EM, Young WF: Cervical spondylotic myelopathy: a brief review of its pathophysiology, clinical course, and diagnosis. Neurosurgery 60 (1 Supp1 1):S35-S41, 2007

5. Behrbalk E, Salame K, Regev GJ, Keynan O, Boszczyk B, Lidar Z: Delayed diagnosis of cervical spondylotic myelopathy by primary care physicians. Neurosurg Focus 35(1):E1, 2013

6. Benzel EC, Lancon J, Kesterson L, Hadden T: Cervical laminectomy and dentate ligament section for cervical spondylotic myelopathy. J Spinal Disord 4:286-295, 1991

7. Berge J, Marque B, Vital JM, Sénégas J, Caillé JM: Agerelated changes in the cervical spines of front-line rugby players. Am J Sports Med 27:422-429, 1999

8. Boden SD, McCowin PR, Davis DO, Dina TS, Mark AS, Wiesel S: Abnormal magnetic-resonance scans of the cervical spine in asymptomatic subjects. A prospective investigation. J Bone Joint Surg Am 72:1178-1184, 1990

9. Bogduk N, Amevo B, Pearcy M: A biological basis for instantaneous centres of rotation of the vertebral column. Proc Inst Mech Eng H 209:177-183, 1995

10. Brazier JE, Harper R, Jones NMB, O'Cathain A, Thomas $\mathrm{KJ}$, Usherwood T, et al: Validating the SF-36 health survey questionnaire: new outcome measure for primary care. BMJ 305:160-164, 1992

11. Breig A, Turnbull I, Hassler O: Effects of mechanical stresses on the spinal cord in cervical spondylosis. A study on fresh cadaver material. J Neurosurg 25:45-56, 1966

12. Carreon LY, Glassman SD, Campbell MJ, Anderson PA: Neck Disability Index, short form-36 physical component summary, and pain scales for neck and arm pain: the minimum clinically important difference and substantial clinical benefit after cervical spine fusion. Spine J 10:469-474, 2010

13. Cho W, Eid AS, Chang UK: The use of pedicle screw-rod system for the posterior fixation in cervico-thoracic junction. J Korean Neurosurg Soc 48:46-52, 2010

14. Clarke E, Robinson PK: Cervical myelopathy: a complication of cervical spondylosis. Brain 79:483-510, 1956

15. Dubousset J: Three-dimensional analysis of the scoliotic deformity, in Weinstein S (ed): The Pediatric Spine: Principles and Practices. New York: Raven Press: pp 479-496, 1994

16. Dvorák J, Antinnes JA, Panjabi M, Loustalot D, Bonomo M: Age and gender related normal motion of the cervical spine. Spine (Phila Pa 1976) 17 (10 Suppl):S393-S398, 1992

17. Dvorák J, Panjabi MM, Grob D, Novotny JE, Antinnes JA: Clinical validation of functional flexion/extension radiographs of the cervical spine. Spine (Phila Pa 1976) 18:120127,1993

18. Dvorák J, Panjabi MM, Novotny JE, Antinnes JA: In vivo flexion/extension of the normal cervical spine. J Orthop Res 9:828-834, 1991

19. Ebara S, Harada T, Yamazaki Y, Hosono N, Yonenobu K, Hiroshima K, et al: Unstable cervical spine in athetoid cerebral palsy. Spine (Phila Pa 1976) 14:1154-1159, 1989

20. el-Mallakh RS, Rao K, Barwick M: Cervical myelopathy secondary to movement disorders: case report. Neurosurgery 24:902-905, 1989

21. Fehlings MG, Wilson JR, Kopjar B, Yoon ST, Arnold PM, Massicotte EM, et al: Efficacy and safety of surgical decompression in patients with cervical spondylotic myelopathy: results of the AOSpine North America prospective multicenter study. J Bone Joint Surg Am 95:1651-1658, 2013

22. Fujimori T, Le H, Ziewacz JE, Chou D, Mummaneni PV: Is there a difference in range of motion, neck pain, and outcomes in patients with ossification of posterior longitudinal ligament versus those with cervical spondylosis, treated with plated laminoplasty? Neurosurg Focus 35(1):E9, 2013

23. Gore DR, Sepic SB, Gardner GM: Roentgenographic findings of the cervical spine in asymptomatic people. Spine (Phila Pa 1976) 11:521-524, 1986

24. Grüninger W, Gruss P: Stenosis and movement of the cervical spine in cervical myelopathy. Paraplegia 20:121-130, 1982

25. Hagenah JM, Vieregge A, Vieregge P: Radiculopathy and myelopathy in patients with primary cervical dystonia. Eur Neurol 45:236-240, 2001

26. Hart RA, Tatsumi RL, Hiratzka JR, Yoo JU: Perioperative complications of combined anterior and posterior cervical decompression and fusion crossing the cervico-thoracic junction. Spine (Phila Pa 1976) 33:2887-2891, 2008

27. Hughes JT, Brownell B: Necropsy observations on the spinal cord in cervical spondylosis. Riv Patol Nerv Ment 86:196204, 1965

28. Kalsi-Ryan S, Karadimas SK, Fehlings MG: Cervical spondylotic myelopathy: the clinical phenomenon and the current pathobiology of an increasingly prevalent and devastating disorder. Neuroscientist 19:409-421, 2013

29. Karadimas SK, Erwin WM, Ely CG, Dettori JR, Fehlings MG: Pathophysiology and natural history of cervical spondylotic myelopathy. Spine (Phila Pa 1976) 38 (22 Suppl 1):S21-S36, 2013

30. Klineberg E: Cervical spondylotic myelopathy: a review of the evidence. Orthop Clin North Am 41:193-202, 2010

31. Kreshak JL, Kim DH, Lindsey DP, Kam AC, Panjabi MM, Yerby SA: Posterior stabilization at the cervicothoracic junction: a biomechanical study. Spine (Phila Pa 1976) 27:27632770, 2002

32. Lee SW, Draper ER, Hughes SPF: Instantaneous center of 
rotation and instability of the cervical spine. A clinical study. Spine (Phila Pa 1976) 22:641-648, 1997

33. Matsumoto M, Okada E, Ichihara D, Chiba K, Toyama Y, Fujiwara H, et al: Modic changes in the cervical spine: prospective 10-year follow-up study in asymptomatic subjects. J Bone Joint Surg Br 94:678-683, 2012

34. Matsunaga S, Komiya S, Toyama Y: Risk factors for development of myelopathy in patients with cervical spondylotic cord compression. Eur Spine J 24 (Suppl 2):142-149, 2015

35. Matz PG, Anderson PA, Holly LT, Groff MW, Heary RF, Kaiser MG, et al: The natural history of cervical spondylotic myelopathy. J Neurosurg Spine 11:104-111, 2009

36. McKinley S, Levine M: Cubic Spline Interpolation. (http:// msemac.redwoods.edu/ darnold/math45/laproj/Fall98/ SkyMeg/Proj.pdf) [Accessed May 28, 2015]

37. Moore AP, Blumhardt LD: A prospective survey of the causes of non-traumatic spastic paraparesis and tetraparesis in 585 patients. Spinal Cord 35:361-367, 1997

38. Morio Y, Yamamoto K, Teshima R, Nagashima H, Hagino $\mathrm{H}$ : Clinicoradiologic study of cervical laminoplasty with posterolateral fusion or bone graft. Spine (Phila Pa 1976) 25:190-196, 2000

39. Morishita Y, Naito M, Hymanson H, Miyazaki M, Wu G, Wang JC: The relationship between the cervical spinal canal diameter and the pathological changes in the cervical spine. Eur Spine J 18:877-883, 2009

40. Muhle C, Wiskirchen J, Weinert D, Falliner A, Wesner F, Brinkmann G, et al: Biomechanical aspects of the subarachnoid space and cervical cord in healthy individuals examined with kinematic magnetic resonance imaging. Spine (Phila Pa 1976) 23:556-567, 1998

41. Northover JR, Wild JB, Braybrooke J, Blanco J: The epidemiology of cervical spondylotic myelopathy. Skeletal Radiol 41:1543-1546, 2012

42. Nurick $\mathrm{S}$ : The pathogenesis of the spinal cord disorder associated with cervical spondylosis. Brain 95:87-100, 1972

43. O'Connell J, Brain R, Ritchie R, Miller H: Discussion on cervical spondylosis. Proc R Soc Med 49:197-208, 1956

44. Oshima Y, Seichi A, Takeshita K, Chikuda H, Ono T, Baba S, et al: Natural course and prognostic factors in patients with mild cervical spondylotic myelopathy with increased signal intensity on T2-weighted magnetic resonance imaging. Spine (Phila Pa 1976) 37:1909-1913, 2012

45. Panjabi MM: Centers and angles of rotation of body joints: a study of errors and optimization. J Biomech 12:911-920, 1979

46. Park MS, Mesfin A, Stoker GE, Song KS, Kennedy C, Riew KD: Sagittal range of motion after extensive cervical fusion. Spine J 14:338-343, 2014

47. Pearcy MJ, Bogduk N: Instantaneous axes of rotation of the lumbar intervertebral joints. Spine (Phila Pa 1976) 13:10331041, 1988

48. Pyeritz RE, Sack GH Jr, Udvarhelyi GB: Genetics clinics of The Johns Hopkins Hospital. Surgical intervention in achondroplasia. Cervical and lumbar laminectomy for spinal stenosis in achondroplasia. Johns Hopkins Med J 146:203-206, 1980

49. Ramieri A, Domenicucci M, Ciappetta P, Cellocco P, Raco A, Costanzo G: Spine surgery in neurological lesions of the cervicothoracic junction: multicentric experience on 33 consecutive cases. Eur Spine J 20 (Suppl 1):S13-S19, 2011

50. Reid JD: Effects of flexion-extension movements of the head and spine upon the spinal cord and nerve roots. J Neurol Neurosurg Psychiatry 23:214-221, 1960

51. Sadasivan KK, Reddy RP, Albright JA: The natural history of cervical spondylotic myelopathy. Yale J Biol Med 66:235242,1993

52. Sakou T: [Surgery of the Cervical Spine.] Tokyo: Kanehara, 1989, pp 141-157 (Jpn)
53. Scheer JK, Tang JA, Smith JS, Acosta FL Jr, Protopsaltis TS, Blondel B, et al: Cervical spine alignment, sagittal deformity, and clinical implications: a review. J Neurosurg Spine 19:141-159, 2013

54. Shinomiya K, Mutoh N, Furuya K: Study of experimental cervical spondylotic myelopathy. Spine (Phila Pa 1976) 17 (10 Suppl):S383-S387, 1992

55. Smith JS, Lafage V, Ryan DJ, Shaffrey CI, Schwab FJ, Patel AA, et al: Association of myelopathy scores with cervical sagittal balance and normalized spinal cord volume: analysis of 56 preoperative cases from the AOSpine North America Myelopathy study. Spine (Phila Pa 1976) 38 (22 Suppl 1):S161-S170, 2013

56. Soudan K, Dierckx P: Calculation of derivatives and Fourier coefficients of human motion data, while using spline functions. J Biomech 12:21-26, 1979

57. Soudan K, Van Audekercke R, Martens M: Methods, difficulties and inaccuracies in the study of human joint kinematics and pathokinematics by the instant axis concept. Example: the knee joint. J Biomech 12:27-33, 1979

58. Stemper BD, Yoganandan N, Pintar FA, Maiman DJ: The relationship between lower neck shear force and facet joint kinematics during automotive rear impacts. Clin Anat 24:319-326, 2011

59. Tang JA, Scheer JK, Smith JS, Deviren V, Bess S, Hart RA, et al: The impact of standing regional cervical sagittal alignment on outcomes in posterior cervical fusion surgery. Neurosurgery 71:662-669, 2012

60. Taylor AR: The mechanism of injury to the spinal cord in the neck without damage to vertebral column. J Bone Joint Surg Br 33-B:543-547, 1951

61. Toledano M, Bartleson JD: Cervical spondylotic myelopathy. Neurol Clin 31:287-305, 2013

62. Vernon H: The Neck Disability Index: state-of-the-art, 19912008. J Manipulative Physiol Ther 31:491-502, 2008

63. Vernon H, Mior S: The Neck Disability Index: a study of reliability and validity. J Manipulative Physiol Ther 14:409415, 1991

64. Yoshii J, Traynelis VC: Achondroplasia and cervical laminoplasty. J Neurosurg Spine 11:417-420, 2009

65. Young WF: Cervical spondylotic myelopathy: a common cause of spinal cord dysfunction in older persons. Am Fam Physician 62:1064-1070, 1073, 2000

66. Yukawa Y, Kato F, Suda K, Yamagata M, Ueta T: Age-related changes in osseous anatomy, alignment, and range of motion of the cervical spine. Part I: Radiographic data from over 1,200 asymptomatic subjects. Eur Spine J 21:1492-1498, 2012

\section{Disclosure}

The views expressed in this article are those of the author and do not necessarily reflect the official policy or position of the Department of the Navy, Department of Defense, nor the US Government.

This study was sponsored by AOSpine North America, Inc., a nonprofit 501(c)(3) corporation. Dr. Shaffrey is a consultant at Biomet, Globus, Medtronic, NuVasive, and Stryker. He has direct stock ownership in NuVasive. He is a patent holder and/ or receives royalties from Biomet, Medtronic, and NuVasive. Dr. Ames is an employee of UCSF and a consultant at DePuy, Stryker, and Medtronic. He has direct stock ownership in Doctors Research Group, Baxano Surgical, and Visualase. He is a patent holder for Fish \& Richardson, P.C. and has received royalties from Biomet Spine and Aesculap. Dr. Smith is an employee of UVA and a consultant at Biomet, NuVasive, DePuy, Medtronic, Globus, and Cerapedics. He has received clinical or research support from DePuy/ISSGF. He has received clinical or research support for this study (includes equipment or 
material) from AOSpine North America. Dr. Arnold is a consultant at Medtronic Sofamor Danek, Stryker Spine, FzioMed, and AOSpine North America. He has direct stock ownership in Z-plasty. Dr. Massicotte is a consultant at Watermark Research. $\mathrm{He}$ has received institutional support by educational grants from Medtronic, DePuy-Synthes Canada, and Zimmer. Dr. Lafage has received clinical or research support for this study (includes equipment or material) from AOSpine North America. Dr.

Schwab has received clinical or research support for this study (includes equipment or material) from AOSpine North America. Dr. Protopsaltis is a consultant at Medicrea, Biomet Spine, and DePuy Synthes Spine. He has received clinical or research support from Zimmer Spine. Dr. Radcliff is a consultant at DePuy, Globus, and Medtronic Advanced Energy. He is a patent holder for Globus and has received clinical or research support for this study (includes equipment or material) from Globus, DePuy, Medtronic, and Paradigm.

\section{Author Contributions}

Conception and design: V Lafage, Liu, R Lafage, Smith, Protopsaltis, Challier, Ames. Acquisition of data: V Lafage, Smith, Shaffrey, Arnold, Chapman, Massicotte, Yoon, Fehlings, Ames. Analysis and interpretation of data: V Lafage, Liu, R Lafage, Protopsaltis, Challier. Drafting the article: V Lafage, Liu, R Lafage, Challier. Critically revising the article: all authors. Reviewed submitted version of manuscript: all authors. Approved the final version of the manuscript on behalf of all authors: V Lafage. Statistical analysis: V Lafage, Liu, Protopsaltis, Yoon. Administrative/technical/material support: V Lafage, Liu, R Lafage, Smith, Protopsaltis, Schwab, Ames. Study supervision: V Lafage, Smith, Ames.

\section{Correspondence}

Virginie C. Lafage, Department of Orthopaedic Surgery, New York University Hospital for Joint Diseases, 306 E. 15th St., Ste. 1F, New York, NY 10003. email: virginie.lafage@gmail.com. 